\title{
A pesquisa extensionista em comunidades de faxinais: o estado da arte e a contribuição da UEPG
}

\section{Extension research in Faxinal communities: the state of art and the contribution of the State University of Ponta Grossa, Paraná}

\author{
Cicilian Luiza Löwen Sahr \\ Universidade Estadual de Ponta Grossa
}

\begin{abstract}
Resumo: Comunidades de faxinais encontram-se inseridas no cenário regional da Universidade Estadual de Ponta Grossa (UEPG). Todavia, projetos acadêmicos voltados a estas comunidades regionais emergem apenas a partir de 2000. Neste artigo, busca-se delinear a caminhada da UEPG em termos de pesquisa e extensão com relação a estas comunidades, apontando o estado da arte e a contribuição da Instituição para o debate do tema. Tal caminhada, entretanto, não pode ser entendida como uma caminhada isolada, ela se soma a de outras universidades regionais, bem como, a de institutos de pesquisa e extensão com inserção regional.
\end{abstract}

Palavras-chave: Pesquisa. Extensão. Faxinais. Estado da arte. UEPG.

\begin{abstract}
Faxinal communities have been a part of the regional scenario of the State University of Ponta Grossa (UEPG) for a long time. Academic projects on these regional communities, however, have only appeared since 2000. In this article, the evolution of the research and extension activities of the UEPG on these communities has been traced, evaluating the state of art and its contribution. Such na evolution cannot simply be understood as an isolated effort, but has to be contextualized together with other regional universities and other research and extension institutions with regional impact.
\end{abstract}

Keywords: Extension research. Faxinal. State of art. State University of Ponta Grossa. 


\section{INTRODUÇÃO}

As comunidades de faxinais, caracterizadas pela atividade silvipastoril e pelo uso comum da terra, estão presentes no cenário regional no qual a Universidade Estadual de Ponta Grossa (UEPG) também está inserida. Todavia, embora a UEPG tenha se constituíd o enquanto universidade no final da década de 1960, os projetos de pesquisa e extensão voltados a estas comunidades regionais emergem apenas a partir do ano de 2000.

Neste artigo, busca-se delinear a caminhada da UEPG em termos de pesquisa e extensão com relação às comunidades de faxinais, apontando o estado da arte e a contribuição da UEPG para com esta realidade regional. Num primeiro momento, apresenta-se a trajetória dos projetos de pesquisa e extensão. Num segundo momento, apresenta-se o florescimento da formação acadêmica em torno da temática.

É preciso ressaltar, entretanto, que esta caminhada da UEPG não pode ser entendida como uma caminhada isolada, ela se soma à caminhada de outras universidades regionais, a exemplo da Universidade Estadual do Centro-Oeste (UNICENTRO) e da Universidade Federal do Paraná (UFPR), bem como, a de institutos de pesquisa e extensão com inserção regional, como é o caso de órgãos do governo estadual (Secretaria Estadual de Meio Ambiente-SEMA, Instituto Ambiental do Paraná - IAP, entre outros).

\section{A TRAJETÓRIA DOS PROJETOS DE PESQUISA E EXTENSÃO}

A UEPG vem atuando com projetos de pesquisa e extensão em comunidades de faxinais há cerca de uma década. Num primeiro momento os projetos não tinham o faxinal como objeto central, apenas os englobavam dentro do conjunto das comunidades rurais que compõe a região dos Campos Gerais e da Mata com Araucária. É a partir de 2004 que os faxinalenses passam a ser considerados sujeitos nos projetos desenvolvidos (Quadro 01).

O projeto de pesquisa "Patrimônio Cultural e Turismo: Potencialidades e Riscos na Região dos Campos Gerais" (LÖWEN SAHR, 2001) é o marco da inserção da UEPG nos estudos sobre faxinais. Tal projeto, desenvolvido entre 2001 e 2003 com apoio da Fundação Araucária, parte da ideia de que o patrimônio cultural dos Campos Gerais representa um enorme potencial de desenvolvimento para a região e que a diversidade de seus universos simbólicos possibilita a definição de uma paisagem turístico-cultural bastante rica. Nesta perspectiva, as reflexões se voltaram para o estabelecimento de diretrizes que permitissem a construção de uma imagem turístico-cultural para a região (ver SAHR e LÖWEN SAHR, 2001). Tal imagem foi construída com base em dois complexos de narrativas que se apresentam como âncoras de cenários imaginários: as histórias e as etnicidades da sua população local e a formação de espaços sócio-tecnológicos na região. O primeiro complexo referindo-se aos relatos do povoamento e da imigração na região. Neste quadro se destacam, além das tradicionais etnias dos imigrantes (russos-alemães, alemães, poloneses, ucranianos, holandeses e japoneses), os caboclos, os sitiantes e os fazendeiros, as tribos indígenas, os quilombos, os ciganos e vários outros. $\mathrm{O}$ segundo complexo se volta à apresentação da história econômica e tecnológica da região, com os relatos do tropeirismo, da estrada de ferro, da navegação no rio Iguaçu, da produção ervateira, da mineração de xisto e cal, da agroindústria e das cooperativas, entre outros. 
Quadro 01 - Projetos de Pesquisa e Extensão da UEPG sobre a temática Faxinal - 2001-2011

\begin{tabular}{|c|c|c|c|c|}
\hline Periodo & Título & Categoria & Financiamento & Coordenador \\
\hline 2001-2003 & $\begin{array}{l}\text { Patrimônio Cultural e Turismo: Potencialidades e } \\
\text { Riscos na Região dos Campos Gerais }\end{array}$ & Pesquisa & $\begin{array}{l}\text { Fund. Arau- } \\
\text { cária }\end{array}$ & C. L. LÖWEN SAHR \\
\hline $2002-2004$ & $\begin{array}{l}\text { Gestão Local com Cidadania: Planejamento e Ações } \\
\text { Comunitárias no Município de São João do Triunfo } \\
\text { - PR }\end{array}$ & Extensão & --- & C. L. LÖWEN SAHR \\
\hline $2004-2008$ & $\begin{array}{l}\text { Terras e Povos de Faxinal: apoio e assessoria no reco- } \\
\text { nhecimento de populações tradicionais e territórios } \\
\text { sociais específicos do Bioma Floresta com Araucária } \\
\text { no Paraná }\end{array}$ & Extensão & --- & C. L. LÖWEN SAHR \\
\hline 2004-2007 & $\begin{array}{l}\text { O Sistema Faxinal e sua sustentabilidade enquanto } \\
\text { forma de organização camponesa na região da Mata } \\
\text { de Araucária do Paraná }\end{array}$ & Pesquisa & $\begin{array}{l}\text { Fund. Araucá- } \\
\text { ria e CNPq }\end{array}$ & C. L. LÖWEN SAHR \\
\hline 2007-2009 & $\begin{array}{l}\text { Os 'mundos faxinalenses' da Floresta com Araucária: } \\
\text { uma metodologia para se compreender suas comple- } \\
\text { xidades territoriais }\end{array}$ & Pesquisa & $\mathrm{CNPq}$ & C. L. LÖWEN SAHR \\
\hline 2007-2009 & $\begin{array}{l}\text { Estudo de sistemas silvipastoris nas comunidades fa- } \\
\text { xinalenses da Região Centro-Sul do Estado do Paraná }\end{array}$ & Pesquisa & $\begin{array}{l}\text { Fund. Arau- } \\
\text { cária }\end{array}$ & M. D. LEITE* \\
\hline 2007-2011 & Gestão participativa de recursos naturais em Faxinais & Pesquisa & Capes & M. CARVALHO \\
\hline 2007-2010 & $\begin{array}{l}\text { Ecoturismo como ferramenta de desenvolvimento } \\
\text { sustentável dos Faxinais de Taboãozinho e Barra } \\
\text { Bonita de Prudentópolis - PR }\end{array}$ & Extensão & MMA & V. M. MOREIRA** \\
\hline $2008-2010$ & $\begin{array}{l}\text { Estudo comparativo dos processos pedogeomorfoló- } \\
\text { gicos ocorrentes em Terras de Faxinais e outros siste- } \\
\text { mas de uso do solo e ocupação da terra }\end{array}$ & Pesquisa & --- & M. L. C. PINTO \\
\hline $2008-$ & $\begin{array}{l}\text { Faxinalenses e Quilombolas: apoio e assessoria ao } \\
\text { reconhecimento de populações e territórios tradicio- } \\
\text { nais no Paraná }\end{array}$ & Extensão & --- & C. L. LÖWEN SAHR \\
\hline 2009- & $\begin{array}{l}\text { Compreendendo 'geograficidades existenciais' de } \\
\text { povos e comunidades tradicionais: quilombolas e } \\
\text { faxinalenses no Paraná }\end{array}$ & Pesquisa & & C. L. LÖWEN SAHR \\
\hline 2010- & $\begin{array}{l}\text { Interações comunidade-solos-floresta em faxinal } \\
\text { paranaense: sustentabilidade geoecológica e usos } \\
\text { coletivos da paisagem }\end{array}$ & Pesquisa & $\begin{array}{l}\text { Fund. Arau- } \\
\text { cária }\end{array}$ & N. FLORIANI \\
\hline 2010- & página http://faxinais.wordpress.com/ & Extensão & --- & E. STRUMINSKI \\
\hline 2011 & $\begin{array}{l}\text { I Simpósio de Pesquisadores de Faxinais: Estado da } \\
\text { Arte e Perspectivas }\end{array}$ & Extensão & $\begin{array}{l}\text { Fund. Arau- } \\
\text { cária }\end{array}$ & Diversos $* * *$ \\
\hline
\end{tabular}

Nota: $\left(^{*}\right)$ Projeto do IAPAR com parceria da UEPG $\left(^{* *}\right)$ Projeto do ING com parceria da UEPG $\left({ }^{* * *}\right)$ Projeto conjunto com a Unicentro e com parceria da UFPR

Fonte: Plataforma Lattes CNPq.

É dentro deste projeto que se evidencia a inserção da UEPG nos estudos de faxinais. $\mathrm{Na}$ imagem turística construída para os Campos Gerais eles estariam enquadrados na região dos caboclos e no complexo da produção da erva-mate (ver SAHR e LÖWEN SAHR, 2001). Salientava-se que o processo de expansão da colonização européia teria expulsado uma parcela significativa da população local para as matas mais densas próximas da Serra Geral e da Escarpa
Devoniana. Esta população teria sobrevivido com base na agricultura mista de subsistência, na extração de erva mate e na criação solta de suínos, desenvolvidas em sistema de Faxinais. Eles seriam encontrados ainda, em sua maioria, nos municípios de Ivaí, Prudentópolis, Rio Azul, Rebouças, Teixeira Soares etc., mas também na Lapa, em Palmeira, Ponta Grossa e Piraí do Sul. O complexo da produção de erva-mate, menos presente no imaginário turístico, apesar 
de se mostrar com potencial igualmente importante, estaria presente na região entre Ponta Grossa e União da Vitória, cuja ecologia mista com extração de erva-mate, baseada numa cultura cabocla, se apresentaria extremamente adaptada a um turismo ecológico. Nesta região ainda poderiam ser encontrados carijós, barbaquás e canchas para tratamento das folhas da erva.

Dos contatos e redes tecidas durante a elaboração deste projeto de pesquisa, construiu-se o projeto de extensão "Gestão Local com Cidadania: Planejamento e Ações Comunitárias no Município de São João do Triunfo - PR" (LÖWEN SAHR, 2002). O projeto, desenvolvido entre $2002 \mathrm{e}$ 2004, procurou incentivar junto ao município de São João do Triunfo, a utilização de suas potencialidades de desenvolvimento local. A ideia do projeto era a de propiciar ao município - através de ações ligadas ao planejamento municipal - a gestão turístico-cultural e a educação - a formação e capacitação de recursos humanos, a busca pelo cooperativismo e associativismo e também, a geração de trabalho e renda. No eixo <planejamento municipal〉 procurou-se desenvolver um trabalho de conscientização acerca da importância deste, a elaboração de material-base para este planejamento e o treinamento da aplicação da técnica "metaplan" neste processo. No eixo 〈gestão turístico-cultural〉 procurou-se dar apoio à implantação do Plano Nacional de Municipalização do Turismo (PNMT) e desenvolver ações no trecho de maior potencial turístico do município, localizado entre a área central e a Vila Palmira, antigo porto fluvial. No eixo 〈educação〉 acompanhou-se a experiência desenvolvida na comunidade, intitulada “Túnel do Tempo", que numa perspectiva reconstrutivista levava os alunos das escolas locais a construir vasos comunicantes entre passado e presente através de exposições e encenações sobre seu espaço e sua cultura. A atuação integrada nos três eixos foi a tônica do projeto.

A presença faxinalense, que propiciou a transversalidade entre os eixos, destacou-se durante a realização do "Inventário Turístico - São João do Triunfo - PR" (LÖWEN SAHR e al, 2003), quando elaborou-se, entre outros, uma caracterização de todas as localidades rurais do município. Neste momento evidenciou-se que a grande maioria destas foram antigos faxinais, como no caso das localidades de Barra Bonita, Faxinal dos Lapeanos, Rio Baio, Faxinal dos Fabrícios, Taquaruçu, Guaiaca dos Pretos, Bolo Grande, Boa Vista, Faxinal dos Andrade, Faxinal dos Rodrigues, Faxinal dos Ferreira, Faxinal dos Mineiros, Faxinal do Louro, Coxilhão das Ameixeiras e Meia Lua. Em duas destas localidades foram encontrados faxinais em funcionamento: o Faxinal do Seixas e o Faxinal do Rio do Poço.

Outro projeto de extensão derivado do "Patrimônio Cultural e Turismo: Potencialidades e Riscos na Região dos Campos Gerais" foi a participação de professores da UEPG na equipe de elaboração do "Plano Diretor de Turismo de Ponta Grossa" em 2002. Neste Plano foi elaborado por Wolf-Dietrich Sahr, professor da Universidade Federal do Paraná (UFPR) e integrante do referido projeto de pesquisa da UEPG, uma "Regionalização Sócio-Cultural" do Município de Ponta Grossa em que se destacou uma região de Floresta com Araucária no Distrito de Itaiacoca como uma região de faxinais.

Esta "(re)descoberta" dos faxinais levou a Prefeitura Municipal de Ponta Grossa (PMPG), através da Secretaria Municipal de Agricultura e Abastecimento, a contatar a UEPG para a realização de um estudo sobre os faxinais no seu município. $\mathrm{O}$ resultado do estudo foi a elaboração de um projeto de extensão que resultou num relatório intitulado "O Sistema Faxinal no Município de Ponta Grossa: Diretrizes para 
a preservação do ecossistema, do modo de vida, da cultura e das identidades das comunidades e dos espaços faxinalenses" (ver LÖWEN SAHR e IEGELSKI, 2003).

Neste relatório buscou-se, num primeiro momento, a apresentação do sistema faxinal enquanto forma de organização camponesa no Paraná. Foram analisados aspectos conceituais, históricos, geográficos, sociológicos e estatísticos deste sistema no Paraná. Num segundo momento, aprofundou-se a análise para o Município de Ponta Grossa, descrevendo-se a trajetória dos faxinais na última década. Destacou-se, sobretudo, os sete faxinais, que segundo levantamento da Emater em 1994, ainda mantinham seus criadouros coletivos: Antunes, Caçador dos Cassimiro, Caçador dos Gonçalves, Carandá, Carazinho, Mato Queimado e Sete Saltos de Baixo. Apontaram-se suas características, seus percursos e as causas da dissolução da grande maioria destes na década que se seguiu. No terceiro momento, a avaliação concentrou-se no Faxinal de Sete Saltos de Baixo, por trata-se do único remanescente do município, considerando-se a existência dos dois espaços característicos apontados para o sistema, as terras de plantar e as terras de criar, delimitados entre si por cercas e valos. Por fim, na quarta parte, foram apontadas diversas diretrizes para a preservação deste sistema (LÖWEN SAHR e IEGELSKI, 2003).

Entre as diretrizes apontadas pelo relatório (ver LÖWEN SAHR e IEGELSKI, 2003), a que teve efeito imediato pela PMPG foi a solicitação de cadastro do Faxinal Sete Saltos de Baixo como Área Especial de Uso Regulamentado (ARESUR) junto ao Instituto Ambiental do Paraná (IAP). Em 1997, através do Decreto n. 3.446, o Governo do Estado do Paraná reconheceu formalmente a existência dos faxinais e criou a ARESUR para poder categorizá-los. Assim, os municípios que possuem faxinais em seus territórios adquiriram o direito de receber, pela lei do ICMS Ecológico, maior repasse de recursos do governo estadual. Esta solicitação foi negada num primeiro momento, mas posteriormente o processo foi reaberto, entretanto, até hoje nenhuma ação concreta se efetivou por parte do IAP. Os governos municipais que sucederam ao relatório, quando procurados pela UEPG apontaram não ter a questão dos faxinais como prioridade, isentando-se de qualquer responsabilidade.

Diante da demanda de uma maior aproximação da UEPG de sua realidade regional, desde 2004 se mantêm na instituição projetos de extensão voltados aos faxinais, agregando uma equipe de pesquisadores extensionistas. Entre 2004 e 2008, o projeto de extensão intitulou-se "Terras e Povos de Faxinal: apoio e assessoria no reconhecimento de populações tradicionais e territórios sociais específicos do Bioma Floresta com Araucária no Paraná" (LÖWEN SAHR, 2004).

Entre os anos de 2004 e 2007 consolida-se também a pesquisa de faxinais na UEPG. O projeto de pesquisa "O Sistema Faxinal e sua sustentabilidade enquanto forma de organização camponesa na região da Mata de Araucária do Paraná" (LÖWEN SAHR, 2004), recebeu fomento tanto da Fundação Araucária, na esfera estadual, quanto do Conselho Nacional de Desenvolvimento Científico e Tecnológico (CNPq). Uma equipe de pesquisadores local voltou-se para a temática. Este projeto objetivava o estudo do faxinal enquanto um sistema silvipastoril tradicional encontrado na região Centro-Sul do Paraná. Partia-se de alguns pressupostos, entre eles, os de que: a) o sistema fora implantado inicialmente no contexto cultural dos caboclos, mas que, na metade do século XIX fora também absorvido pelos imigrantes poloneses e ucranianos; b) nele se mantinha um grande número de técnicas agropecuárias tradicionais, costumes e tradições, além de 
formas de expressão religiosas populares; e c) de que esta forma de uso do solo, pela sua adaptação ecológica e também integração social, parecia cumprir critérios de sustentabilidade. Desta forma, a questão central da investigação era a de analisar a sustentabilidade sociocultural, econômica, política e ambiental do sistema faxinal no estado do Paraná.

A atenção que os faxinais haviam recebido da academia até aquele momento era bastante pequena apesar de sua relativa frequência na região Centro-Sul do estado, restringindo-se quase que exclusivamente aos trabalhos de Chang ${ }^{1}$ de 1988 e de Nerone $^{2}$ de 2000. Naquele momento, ou seja, a partir de 2004, evidenciava-se uma lenta retomada da discussão sobre os faxinais em meios técnicos e científicos específicos. Bastante interessante, entretanto, era o fato de que esta forma de uso do solo, pela sua adaptação ecológica e também integração social, parecia cumprir critérios de sustentabilidade, discussão que havia mobilizado a academia na década de 1990. Em termos políticos, os faxinais continuavam a sofrer pressão em função do processo demodernização do campo instalado em todo o território nacional. Todavia, assistia-se certo reavivar da agricultura familiar, em que se acreditava que os faxinais poderiam vir novamente a encontrar espaço político.

O projeto "O Sistema Faxinal e sua sustentabilidade enquanto forma de organização camponesa na região da Mata de Araucária do Paraná" contou com a participação de Arne Egger, um doutorando da Universidade de Heidelberg (Alemanha), que estudou o Faxinal Sete Saltos de Baixo no Primeiro Planalto

${ }^{1}$ CHANG, Man Yu. Sistema Faxinal: uma forma de organização camponesa em desagregação no Centro-sul do Paraná. Londrina: IAPAR, 1988. 124p.

${ }^{2}$ NERONE, Maria Magdalena. Terras de Plantar, Terras de Criar - Sistema Faxinal: Rebouças - 1950-1997. 2000.286f. (Doutorado em História) - Programa de Pós-Graduação da Faculdade de Ciências e Letras da Universidade Estadual Paulista, Campus de Assis, São Paulo, 2000.
Paranaense, o Faxinal Anta Gorda no Segundo e o Faxinal Saudade Santa Anita no Terceiro. A tese de Egger, datada de 2009 eintitulada "Geoökologische Untersuchung des Faxinal-Waldweidesystems der Hochländer von Paraná, Südbrasilien" (trad.“Investigação geoecológica do sistema silvipastoril Faxinal dos Planaltos do Paraná, Sul do Brasil"), buscou entender a sustentabilidade do sistema, avaliando a resistência dos ecossistemas florestais às interferências antrópicas. Para tanto, pesquisou a associação e a dinâmica das catenas pedológicas, a combinação florestal das comunidades ecológicas e a dinâmica de uso do solo e suas interrelações com os componentes anteriormente apontados.

Uma ampla rede de contatos foi tecida durante a fase de desenvolvimento do projeto. Um novo levantamento da situação dos faxinais no Paraná encontrava-se em execução pelo IAP, vindo a retratar a resistência de 44 faxinais no estado. A exposição dos resultados preliminares desta pesquisa do IAP ocorreu em julho de 2004 na cidade de Rebouças, ocasião em que foi criada a "Rede Faxinal". Esta rede atuou na defesa e promoção das terras e povos de Faxinal. Ela envolveu representantes de órgãos do governo estadual (SEMA, IAP, Secretária Estadual de Abastecimento SEAB, IAPAR, etc.) e federal (EMBRAPA), de prefeituras municipais (Ponta Grossa, Rebouças, etc.), de instituições de ensino/ pesquisa (UEPG, UNICENTRO, etc.), de organizações não governamentais (Instituto Guardiões da Natureza - ING, Instituto Equipe de Educação Popular - IEEP, etc.), como também - e principalmente - membros das comunidades faxinalenses. A atuação desta rede culminou na organização do I Encontro de Povos de Faxinais, ocorrido em Irati em agosto de 2005.

Em 2005, após o I Encontro dos Povos de Faxinais, os faxinalenses foram integrados à Comissão Nacional de Desenvolvimento 
Sustentável dos Povos e Comunidades Tradicionais, criada em 2004 com base no Decreto Presidencial de 27 de Dezembro. Isto se tornou oficial pelo Decreto de 13 de Julho de 2006 (Art. 4, inc. XXI) que deu representação à Rede Faxinal na referida comissão. Paralelamente aos acontecimentos nacionais, estrutura-se a organização do movimento "Articulação-Puxirão", fomentada e assessorada pelo IEEP, agregando os povos faxinalenses.

Ainda em 2005, visando produzir uma base científica de apoio às comunidades de faxinais, os pesquisadores atuantes e presentes no I Encontro de Povos de Faxinais se reuniram e na ocasião criaram a "Rede Faxinal Pesquisa". Esta rede, com caráter multidisciplinar (engenheiros florestais, zootecnistas, geógrafos, biólogos, turismólogos, etc.), agregou pesquisadores de instituições e também pesquisadores autônomos, tendo por objetivo estimular as reflexões acadêmicas em torno dos faxinais. Diferentes temáticas relacionadas aos faxinais foram sendo debatidas, entre elas: a dinâmica histórica dos faxinais, questões fundiárias específicas, experiências de regeneração de florestas e de suinocultura ao ar livre, experiências de ONGs, experiências de ações de prefeituras, experiências de conflitos e de resistência de faxinalenses, metodologias de diagnósticos participativo e geo-ecológico, aplicação de técnicas de Sistema de Informação Geográfica (SIG), entre outros.

Este grupo de pesquisadores, que atuava em diferentes comunidades faxinalenses, muitas vezes de forma disciplinar, decide em 2006 concentrar suas ações em um único faxinal. Após visita de reconhecimento e reunião com a comunidade, decide-se por efetuar um esforço concentrado e interdisciplinar no Faxinal Taquari dos Ribeiros. A ideia era desenvolver uma metodologia de pesquisa que pudesse ser replicada a outras comunidades. Dois projetos foram desenvolvidos com este intuito: “Os 'mundos faxinalenses' da Floresta com Araucária: uma metodologia para se compreender suas complexidades territoriais" $\mathrm{e}$ "Estudo de sistemas silvipastoris nas comunidades faxinalenses da Região Centro-Sul do Estado do Paraná".

O projeto "Os 'mundos faxinalenses' da Floresta com Araucária: uma metodologia para se compreender suas complexidades territoriais" (LÖWEN SAHR, 2007), desenvolveu-se entre 2007 e 2009, contando com apoio do CNPq. Buscou estabelecer - em reflexões sobre a dialética e convivência entre o moderno e tradicional, entre as forças da comunidade e as da sociedade, entre funcionalidade e integração - uma metodologia para compreender os "mundos faxinalenses" da Floresta com Araucária do Paraná na sua complexidade.

A metodologia de investigação do projeto priorizou uma visão holística, baseando-se em diferentes níveis interligados através de lógicas diferenciadas, como: a) o nível ecológico, no qual se discute, numa forma sistêmica, os ciclos geoquímicos e as suas funcionalidades, dentro e fora do espaço agrário da comunidade. b) O nível econômico, que se estrutura através de lógicas de subsistência de mercados imediatos (locais, regionais, cooperativistas) e do mercado global. c) O nível social, que se baseia no relacionamento em diferentes unidades sociais (família, grupos, comunidades, cooperativas, município, movimentos sociais), mas também com outros atores como companhias multinacionais, ONGs e Universidades, e d) O nível cultural, que se refere às formas diferentes de percepção do faxinal e atuação na comunidade faxinalense, na sua diversidade ideológica (religião, ideologias sociais, atitudes ambientais, etc.). Como cada lógica segue os seus pressupostos, mas todas regem em conjunto a comunidade, propôs-se uma metodologia interativa, verificando de um lado a lógica interna, mas de outro a influência externa 
("disfuncional") de outras racionalidades e lógicas no conjunto da comunidade (LÖWEN SAHR, 2007).

O projeto "Estudo de sistemas silvipastoris nas comunidades faxinalenses da Região Centro-Sul do Estado do Paraná", desenvolvido entre 2007 e 2009 com apoio da Fundação Araucária, foi coordenado pelo IAPAR (LEITE, 2007), tendo parceria da UEPG. Tal projeto partia do pressuposto de que: a) o "Sistema Silvipastoril Tradicional", que vem sendo utilizado pelos povos faxinalenses desde o início do século XVIII até hoje, com o passar dos anos tem causado danos ao meio ambiente, o que se pode verificar através da degradação dos recursos naturais nos faxinais; b) a utilização de "Sistemas Silvipastoris Tecnificados", que levam em consideração as peculiaridades dos recursos naturais da região - como a integração de árvores, forrageiras e animais - poderiam ser adotados pelos povos faxinalenses de modo a tornar a atividade agropecuária mais produtiva e ecologicamente sustentável.

Assim, o objetivo central da investigação foi o de caracterizar o "Sistema Silvipastoril Tradicional" utilizado pelos povos faxinalenses através de diferentes metodologias: levantamento de campo com coletas de solos, plantas e fezes dos animais; aplicação de questionários; geoprocessamento de imagens; análise laboratorial, etc. Buscou-se obter conhecimentos que pudessem subsidiar estratégias de ação para viabilizar sistemas silvipastoris produtivos e adequados aos faxinais do Paraná na atualidade (LEITE, 2007).

O projeto "Gestão participativa de recursos naturais em Faxinais" (CAMARGO, 2007) se inclui no Programa Nacional de Pós-Doutorado (PNPD) da Coordenação de Aperfeiçoamento de Pessoal de Nível Superior (CAPES) tendo possibilitado a participação de dois doutores em estágio pós-doutoral junto ao Mestrado em
Gestão do Território da UEPG no período de 2007-2011: Dr. Nicolas Floriani e Dr. Edson Struminski. A proposta de pesquisa visou à elaboração de um modelo síntese dos esquemas cognitivos vernaculares de avaliação e classificação das potencialidades e fragilidades de recursos naturais nas paisagens do Faxinal Taquari dos Ribeiros. Buscou-se, com este projeto, introduzir nas pesquisas de faxinais um recurso teórico-metodológico que fosse capaz de dinamizar o diálogo entre as ciências sociais e naturais. Através de uma abordagem geo-sócio-agronômica, pode-se verificar que na espacialidade das práticas agrícolas emergem novas formas de perceber a complexidade do território e dos sentidos que cada um dos sistemas produz em relação à paisagem (CAMARGO, 2007).

Um projeto de extensão associado à UEPG deu-se através da parceria estabelecida entre o Instituto Guardiões da Natureza (ING) e o Departamento de Turismo. Trata-se do projeto "Ecoturismo como ferramenta de desenvolvimento sustentável dos Faxinais de Taboãozinho e Barra Bonita de Prudentópolis - PR" (ING, 2007).O objetivo do projeto, desenvolvido entre 2007 e 2010, foi desenvolver o "Roteiro dos Faxinais", possibilitando oferecer ao turista urbano e técnico-científico a oportunidade de conhecer essas comunidades tradicionais. As famílias das comunidades escolhidas com potencialidade e interesse em receber turista participaram do curso de "Agente Biodinâmico com ênfase em Ecoturismo", o qual também contou com a participação de professores de turismo na sua concepção e realização. Este projeto contou com financiamento do Ministério do Meio Ambiente (MMA).

O projeto de pesquisa "Estudo comparativo dos processos pedogeomorfológicos ocorrentes em Terras de Faxinais e outros sistemas de uso do solo e ocupação da terra" (PINTO, 2008) vem se desenvolvendo desde 2008. A pesquisa busca entender o 
comportamento da interface solo-relevo em áreas cujo sistema de uso do solo mantém características tradicionais, como no caso dos faxinais, comparando-o com áreas circundantes, onde o manejo do solo é mais tecnificado.

A partir de 2008, o projeto extensionista da UEPG voltado aos faxinais, ampliou-se também para as populações quilombolas, intitulando-se "Faxinalenses e Quilombolas: apoio e assessoria ao reconhecimento de populações e territórios tradicionais no Paraná" (LÖWEN SAHR, 2008). A mesma ampliação pode ser observada nos projetos de pesquisa. Entre as demandas à UEPG, a do Instituto Nacional de Colonização e Reforma Agrária (INCRA) de realização de Relatório Antropológico da comunidade quilombola de São João, localizada no Vale do Ribeira, no Município de Adrianópolis - PR. Este Relatório, assumido por Löwen Sahr e sua equipe, deverá fazer parte do Relatório Técnico de Identificação e Delimitação (RTDI) e visa contribuir para a delimitação de territórios de comunidades remanescentes de quilombos do estado do Paraná, resgatando o direito destas às terras onde historicamente suas famílias têm vivido e resistido à violência da discriminação e da exclusão social.

A experiência vivenciada pela equipe na realização do Relatório Antropológico de transposição do que se chamou de geograficidade histórico-existencial para uma territorialidade político-fundiária foi retratada no livro 3 "Geograficidades quilombolas: estudo etnográfico da comunidade de São João, Adrianópolis - Paraná" (LÖWEN SAHR et al, 2011). É interessante observar que até a década de 1970 esta comunidade quilombola,localizada em plena Mata Atlântica, era organizada em "terras de plantar" e "terras de criar" delimitadas entre si por cercas horizontais ("cercas

${ }^{3}$ LÖWENSAHR, Cicilian Luiza et al. Geograficidades quilombolas: estudo etnográfico da comunidade de São João, Adrianópolis - Paraná. Ponta Grossa: Editora UEPG, 2011. 208p. deitadas"). Os criadouros tinham um caráter coletivo e neles conviviam animais de diferentes espécies, predominando os suínos. Pode-se dizer, portanto, que se trata de um "quilombo-faxinal". Desta forma, as pesquisas atuais vêm se voltando a refletir sobre as questões conceituais destas, até então, "diferentes" populações tradicionais.

O projeto de pesquisa "Compreendendo 'geograficidades existenciais' de povos e comunidades tradicionais: quilombolas e faxinalenses no Paraná" (LÖWEN SAHR, 2009), conta com financiamento da Fundação Araucária e teve início em 2009. Este projeto traz à discussão da UEPG, além dos faxinalenses, novos sujeitos, os quilombolas paranaenses. Nele propõe-se, através de reflexões sobre povos e comunidades tradicionais, compreender a "socialidade" espacial. Busca-se uma relação dialógica sobre "geograficidades" através de dois conceitos geográficos: o "território"; e o "espaço". Tenta-se, assim, respeitar a capacidade intelectual dos quilombolas e faxinalenses nas suas próprias "trajetórias tempo-espaciais" e valorizar as próprias categorias destes frente aos desafios das transformações territoriais do Estado.

As técnicas utilizadas no projeto baseiam-se em ideias da "grounded theory", da hermenêutica objetiva e da descrição densa. Procura-se trabalhar a multiplicidade espacial, isto com a pretensão de dar mais visibilidade às vivências concretas e autônomas dos povos e comunidades tradicionais nos seus próprios espaços, sejam eles ecológicos, religiosos, culturais ou sociais. Segue-se também a tradição dos "community studies", aperfeiçoando-a tanto em termos de contextualização da comunidade, como na inclusão de métodos compreensivos, comum na antropologia, sociologia rural, geografia fenomenológica, história oral, "rapid rural appraisal" etc (LÖWEN SAHR, 2009).

O projeto de pesquisa "Interações comunidade-solos-floresta em faxinal paranaense: sustentabilidade geoecológica e usos 
coletivos da paisagem" (FLORIANI, 2010), conta com apoio da Fundação Araucária e teve início em 2010. Este projeto parte dos seguintes pressupostos: a) a formação espacial dos faxinais resulta na configuração de paisagens que integram, em diferentes níveis de sustentabilidade geoecológica, o ecossistema Floresta com Araucária às pequenas comunidades de agricultores tradicionais que manejam coletivamente seus recursos naturais; $b$ ) as áreas de criadouro comunitário são florestadas e constituem, atualmente, os últimos remanescentes expressivos de Floresta Ombrófila Mista da região, merecendo o status de unidades de conservação estaduais. Por outro lado, aponta-se também que muitos faxinais atualmente ativos tentam adaptar-se aos imperativos da lógica de mercado, à pressão fundiária e a ausência de políticas públicas de desenvolvimento local específicas para esses, transformando, para tanto, sua organização espacial.

O estudo volta-se à realidade do Faxinal Taquari dos Ribeiros que apresenta o seguinte quadro de transformação de seu território: o conjunto de atividades produtivas tradicionais (a criação extensiva, as formas artesanais de extrativismo e os policultivos de subsistência) vem dando lugar aos monocultivos comerciais intensivos (fumicultura, reflorestamentos com espécies exóticas, sojicultura, entre outros cultivos e criações intensivos); o crescimento demográfico e o aumento do preço das terras também exercem pressões sobre a paisagem, causando conflitos entre os moradores e a desintegração da comunidade. Acredita-se que tais processos socioespaciais convergem ao desequilíbrio da relação comunidade-natureza, portanto, busca-seelaborar indicadores de sustentabilidade geoecológica para a paisagem do criadouro comunitário do Faxinal Taquari dos Ribeiros através do estudo da interação entre práticas produtivas, processos pedogeomorfológicos, estrutura e diversidade da comunidade arbórea, isto é, das interações comunidade-solo-floresta (FLORIANI, 2010).

Outro projeto de extensão, este de caráter contínuo, foi a construção de uma ferramenta que reúne a produção científica sobre os faxinais, trata-se da página http:/ / faxinais. wordpress.com/. Esta se dedica a divulgar trabalhos de pesquisa, acadêmicos ou de outra natureza, a respeito de faxinais. Os trabalhos são classificados em sete categorias: cultura, filosofia, legislação, meio biológico, meio físico, meio socioeconômico e turismo. A página é mantida pelo Programa de Pós-Graduação em Geografia - Mestrado em Gestão do Território da UEPG e tem o intuito de dar maior visibilidade ao tema, as pesquisas e aos pesquisadores de faxinais. A concepção desta ferramenta é do Prof. Dr. Edson Struminski, que vem atuando desde 2009 como professor visitante na instituição.

A organização do evento "I Simpósio de Pesquisadores de Faxinais: Estado da Arte e Perspectivas", realizado nos dias 14 e 15 de julho de 2011,apresenta-se também como uma iniciativa da UEPG em parceria com a UNICENTRO, através de seus Programas de Pós-Graduação em Geografia. O evento contou com o apoio da UFPR e da Rede Internacional: Diálogos de Saberes e Práticas Socioambientais (RE-SOA) e buscou abranger todo o universo das instituições de ensino e de pesquisa do estado do Paraná e também de fora dele, instituições nacionais e estrangeiras. O objetivo foi reunir pesquisadores das mais diversas áreas, que investigam a temática dos faxinais. Refletiu-se sobre os trabalhos "pioneiros" sobre faxinais, sistematizou-se a produção científica realizada na última década e foram apontados caminhos para pesquisas futuras.

\section{O FLORESCIMENTO DA FORMAÇÃO ACADÊMICA}

A primeira monografia da UEPG que teve a temática dos faxinais como foco foi apresentada como relatório final de iniciação científica e intitulou-se "Cultura 
cabocla, sistema faxinal e turismo - o Faxinal da Linha Paraná em Prudentópolis" (IEGELSKI, 2002). O estudo, realizado por Francine Iegelski com bolsa da Fundação Araucária, analisou de que forma a cultura cabocla encontrava-se inserida na dinâmica de uma comunidade de ascendência ucraniana e quais seriam as contribuições sociais e culturais do caboclo dentro das relações e articulações do sistema faxinal. Defendia-se a ideia da implantação de um planejamento turístico nos faxinais com base nas necessidades e realidades de cada comunidade faxinalense, aliando isto a uma política que garantisse a permanência destes em suas terras. Esse estudo se inseriu no projeto de pesquisa "Patrimônio Cultural e Turismo: Potencialidades e Riscos na Região dos Campos Gerais" (LÖWEN SAHR, 2001).

Após este estudo pioneiro, novos trabalhos de Iniciação Científica só despontaram a partir de 2005. Essas orientações de iniciação científica apenas vieram a ocorrer quando os projetos de pesquisa passaram a ter o faxinal como temática central. A primeira leva de trabalhos desta natureza desenvolveu-se entre 2005 e 2007, a segunda leva, entre 2008 e 2011. Todo este processo de formação de novos pesquisadores na UEPG desenvolveu-se no interior do quadro de docentes do Departamento de Geociências e vinculados aos cursos de licenciatura e bacharelado em Geografia: Profa. Dra. Cicilian Luiza Löwen Sahr, Profa. Dra. Silvia Méri Carvalho, Prof. Dr. Luiz Alexandre Gonçalves Cunha, Profa. Dra. Maria Ligia Cassol Pinto, Profa. Dr. Selma Regina Aranha Ribeiro e Prof. Dr. Nicolas Floriani.

As Iniciações Científicas da primeira fase estão elencadas no Quadro 02. Estas se vinculam, sobretudo, ao projeto "OSistema Faxinal e sua sustentabilidade enquanto forma de organização camponesa na região da Mata de Araucária do Paraná" (LÖWEN SAHR, 2004). Observa-se que nesta fase os faxinais estudados são diversificados: Faxinal Sete Saltos de Baixo (Ponta Grossa), Faxinal Saudade Santa Anita (Turvo), Faxinal dos Seixas (São João do Triunfo) e Faxinal Paraná-Anta Gorda (Prudentópolis).

Quadro 02 - Iniciações Científicas da UEPG sobre a temática Faxinal - 2005-2007

\begin{tabular}{|c|c|c|c|c|c|}
\hline Acadêmico & Título & Ano & Bolsa & Graduação & Orientador \\
\hline $\begin{array}{l}\text { Rodrigo Rocha } \\
\text { MONTEIRO }\end{array}$ & $\begin{array}{l}\text { O Sistema Faxinal enquanto Forma de Organi- } \\
\text { zação Camponesa: o caso do Faxinal Sete Saltos } \\
\underline{\text { de Baixo em Ponta Grossa - PR }}\end{array}$ & $2005 / 2006$ & $\mathrm{CNPq}$ & $\begin{array}{l}\text { Bach. e Lic. } \\
\text { em Geogra- } \\
\text { fia }\end{array}$ & $\begin{array}{l}\text { C. L. LÖWEN } \\
\text { SAHR }\end{array}$ \\
\hline $\begin{array}{l}\text { Rodrigo Rocha } \\
\text { MONTEIRO }\end{array}$ & $\begin{array}{l}\text { O Faxinal Sete Saltos de Baixo enquanto ARE- } \\
\text { SUR: possibilidades e limites }\end{array}$ & $2006 / 2007$ & $\mathrm{CNPq}$ & $\begin{array}{l}\text { Bach. e Lic. } \\
\text { em Geogra- } \\
\text { fia }\end{array}$ & $\begin{array}{l}\text { C. L. LÖWEN } \\
\text { SAHR }\end{array}$ \\
\hline $\begin{array}{l}\text { Wladimir Teixeira } \\
\text { SCHUSTER }\end{array}$ & $\begin{array}{l}\text { O Desenvolvimento Territorial enquanto pos- } \\
\text { sibilidade para se pensar o futuro dos Faxinais: } \\
\text { reflexões a partir do Faxinal Saudade Santa } \\
\underline{\text { Anita - Turvo (PR) }}\end{array}$ & $2006 / 2007$ & $\mathrm{CNPq}$ & $\begin{array}{l}\text { Bach. em } \\
\text { Geografia }\end{array}$ & $\begin{array}{l}\text { C. L. LÖWEN } \\
\text { SAHR }\end{array}$ \\
\hline $\begin{array}{l}\text { Wladimir Teixeira } \\
\text { SCHUSTER }\end{array}$ & $\begin{array}{l}\text { A Sistema Faxinal enquanto forma de organi- } \\
\text { zação camponesa: o caso do Faxinal Saudade } \\
\text { Santa Anita no Município de Turvo - PR }\end{array}$ & $2007 / 2008$ & UEPG & $\begin{array}{l}\text { Bach. em } \\
\text { Geografia }\end{array}$ & $\begin{array}{l}\text { C. L. LÖWEN } \\
\text { SAHR }\end{array}$ \\
\hline $\begin{array}{l}\text { Tiago Augusto ] } \\
\text { BARBOSA }\end{array}$ & $\begin{array}{l}\text { Caracterização da bacia hidrográfica do Sistema } \\
\text { Faxinal dos Seixas - São João do Triunfo - PR }\end{array}$ & $2006 / 2007$ & UEPG & $\begin{array}{l}\text { Bach. em } \\
\text { Geografia }\end{array}$ & S. M. CARVALHO \\
\hline $\begin{array}{l}\text { Tiago Augusto } \\
\text { BARBOSA }\end{array}$ & $\begin{array}{l}\text { Evolução do uso da terra na bacia hidrográfica } \\
\text { do Sistema Faxinal dos Seixas - São João do } \\
\text { Triunfo PR }\end{array}$ & $2007 / 2008$ & UEPG & $\begin{array}{l}\text { Bach. em } \\
\text { Geografia }\end{array}$ & S. M. CARVALHO \\
\hline Carla Correa PRIETO & $\begin{array}{l}\text { Sistema Faxinal e suas Populações Tradicionais: } \\
\text { exemplos do Faxinal Paraná Anta Gorda, Pru- } \\
\text { dentópolis, Paraná }\end{array}$ & $2006 / 2007$ & UEPG & $\begin{array}{l}\text { Bach. em } \\
\text { Geografia }\end{array}$ & L. A. G. CUNHA \\
\hline
\end{tabular}

Fonte: Plataforma Lattes CNPq. 
A segunda fase, entre 2008 e 2011 (Quadro 3), vinculam-se a diversos projetos: “Os 'mundos faxinalenses' da Floresta com Araucária: uma metodologia para se compreender suas complexidades territoriais" (LÖWEN SAHR, 2007), "Estudo de sistemas silvipastoris nas comunidades faxinalenses da Região Centro-Sul do
Estado do Paraná" (LEITE, 2007) e "Gestão participativa de recursos naturais em Faxinais" (CAMARGO, 2007). Observa-se, entretanto, que os estudos se concentram no Faxinal Taquari dos Ribeiros (Rio Azul), conforme deliberação tomada pela Rede Faxinal Pesquisa.

Quadro 03 - Iniciações Científicas da UEPG sobre a temática Faxinal - 2008-2011

\begin{tabular}{|c|c|c|c|c|c|}
\hline Acadêmico & Título & Ano & Bolsa & $\begin{array}{l}\text { Gradua- } \\
\text { ção }\end{array}$ & Orientador \\
\hline Nayme NEIVERTH & $\begin{array}{l}\text { Fumicultura, Doença e Morte no Faxinal Ta- } \\
\text { quari dos Ribeiros (Rio Azul/PR): Reflexões a } \\
\text { partir da Geografia da Saúde }\end{array}$ & $2008 / 2009$ & $\mathrm{CNPq}$ & $\begin{array}{l}\text { Bach. em } \\
\text { Geografia }\end{array}$ & $\begin{array}{l}\text { C. L. LÖWEN } \\
\text { SAHR }\end{array}$ \\
\hline Nayme NEIVERTH & $\begin{array}{l}\text { Terra e cultura faxinalense: reflexões em torno } \\
\text { de políticas e ações governamentais no Ta- } \\
\text { quari dos Ribeiros (Rio Azul/PR) }\end{array}$ & $2009 / 2010$ & $\mathrm{CNPq}$ & $\begin{array}{l}\text { Bach. em } \\
\text { Geografia }\end{array}$ & $\begin{array}{l}\text { C. L. LÖWEN } \\
\text { SAHR }\end{array}$ \\
\hline $\begin{array}{l}\text { Camila Bittencourt } \\
\text { SILVA }\end{array}$ & $\begin{array}{l}\text { O Sistema Faxinal Taquari dos Ribeiros no } \\
\text { contexto da bacia hidrográfica do rio Taquari } \\
\text { Rio Azul - PR }\end{array}$ & $2008 / 2009$ & UEPG & $\begin{array}{l}\text { Bach. em } \\
\text { Geografia }\end{array}$ & S. M. CARVALHO \\
\hline $\begin{array}{l}\text { Camila Bittencourt } \\
\text { SILVA }\end{array}$ & $\begin{array}{l}\text { Caracterização dos Sistemas de Cultivo e } \\
\text { identificação de práticas conservacionistas nas } \\
\text { terras de Plantar do Sistema Faxinal Taquari } \\
\text { dos Ribeiros Rio Azul, Paraná } \\
\end{array}$ & 2009/2010 & $\begin{array}{l}\text { Fund. } \\
\text { Arau- } \\
\text {-cária }\end{array}$ & $\begin{array}{l}\text { Bach. em } \\
\text { Geografia }\end{array}$ & S. M. CARVALHO \\
\hline $\begin{array}{l}\text { Ana Paula Aparecida } \\
\text { Ferreira ALVES }\end{array}$ & $\begin{array}{l}\text { As Populações Tradicionais nas Políticas } \\
\text { Educacionais: Educação Formal e Informal no } \\
\text { Faxinal Taquari dos Ribeiros Rio Azul/PR }\end{array}$ & $2008 / 2009$ & $\mathrm{CNPq}$ & $\begin{array}{l}\text { Lich. em } \\
\text { Geografia }\end{array}$ & $\begin{array}{l}\text { C. L. LÖWEN } \\
\text { SAHR }\end{array}$ \\
\hline Josiane BELANI & $\begin{array}{l}\text { Os mundos faxinalenses da Floresta com } \\
\text { Araucária: história e representação social no } \\
\text { Faxinal Taquari dos Ribeiros Rio Azul/PR }\end{array}$ & 2008/2009 & $\mathrm{CNPq}$ & $\begin{array}{l}\text { Bach. em } \\
\text { Geografia }\end{array}$ & $\begin{array}{l}\text { C. L. LÖWEN } \\
\text { SAHR }\end{array}$ \\
\hline Tanize TOMASI & $\begin{array}{l}\text { O Tradicional, as Doenças e a Morte em Co- } \\
\text { munidade Faxinalenses: Reflexões a partir da } \\
\text { Geografia da Saúde do Caso do Taquari dos } \\
\underline{\text { Ribeiros (Rio Azul/PR) }}\end{array}$ & 2008/2009 & UEPG & $\begin{array}{l}\text { Bach. em } \\
\text { Geografia }\end{array}$ & $\begin{array}{l}\text { C. L. LÖWEN } \\
\text { SAHR }\end{array}$ \\
\hline $\begin{array}{l}\text { Rogério Gomes dos } \\
\text { SANTOS }\end{array}$ & $\begin{array}{l}\text { Estudo comparativo dos processos pedo- } \\
\text { geomorfogênicos ocorrentes em Terras de } \\
\text { Faxinais e outros sistemas de uso e ocupação } \\
\text { da terra }\end{array}$ & $2008 / 2009$ & $\begin{array}{l}\text { Fund. } \\
\text { Arau- } \\
\text {-cária }\end{array}$ & $\begin{array}{l}\text { Lic. em } \\
\text { Geografia }\end{array}$ & M. L. C. PINTO \\
\hline Anna Paula LOMBARDI & $\begin{array}{l}\text { Estudo comparativo dos processos pedo- } \\
\text { gemorfogênicos ocorrentes em Terras de } \\
\text { Faxinais e outros sistemas de uso e ocupação } \\
\text { da terra }\end{array}$ & $2009 / 2010$ & $\begin{array}{l}\text { Fund. } \\
\text { Arau- } \\
\text {-cária }\end{array}$ & $\begin{array}{l}\text { Bach. em } \\
\text { Geografia }\end{array}$ & M. L. C. PINTO \\
\hline Adelita STANINSKI & $\begin{array}{l}\text { Estudo comparativo dos processos pedogeo- } \\
\text { morfogênicos em Terras de Faxinais: sistema } \\
\text { de uso e ocupação da terra }\end{array}$ & $2009 / 2010$ & UEPG & $\begin{array}{l}\text { Lic. Em } \\
\text { Geografia }\end{array}$ & M. L. C. PINTO \\
\hline Juliano STRACHULSKI & $\begin{array}{l}\text { Mapeamento e Diagnóstico participativo dos } \\
\text { solos do território do Faxinal Taquari dos } \\
\text { Ribeiros, Município de Rio Azul - PR }\end{array}$ & 2009/2010 & UEPG & $\begin{array}{l}\text { Bach. em } \\
\text { Geografia }\end{array}$ & Nicolas FLORIANI \\
\hline Juliano STRACHULSKI & $\begin{array}{l}\text { Plantas indicadoras da qualidade das terras } \\
\text { e etnoconhecimento no Faxinal Taquari dos } \\
\underline{\text { Ribeiros, Município de Rio Azul - PR }}\end{array}$ & $2010 / 2011$ & UEPG & $\begin{array}{l}\text { Bach. em } \\
\text { Geografia }\end{array}$ & Nicolas FLORIANI \\
\hline
\end{tabular}

Fonte: Plataforma Lattes CNPq. 
Grande parte das pesquisas de Iniciação Científica elencadas nos Quadros 02 e 03 foram aprofundadas e complementadas transformando-se em Trabalhos de Conclusão de Curso de licenciatura e bacharelado em Geografia, conforme pode ser observado no Quadro 04. Novos alunos também se vincularam à proposta dos projetos. Observa-se que o direcionamento da
Rede Faxinal Pesquisa repercutiu nos trabalhos que, a partir de 2007, se concentram no Faxinal Taquari dos Ribeiros, enquanto que anteriormente estes eram desenvolvidos nas seguintes comunidades: Faxinal dos Lemes (Ipiranga), Sete Salto de Baixo (Ponta Grossa) e Faxinal Saudade Santa Anita (Turvo).

Quadro 04 - Trabalhos de Conclusão de Curso da UEPG sobre a temática Faxinal - 2005-2011

\begin{tabular}{|c|c|c|c|c|}
\hline Acadêmico & Título & Ano & Curso & Orientador \\
\hline Elaine Cristina LEMES & $\begin{array}{l}\text { Da sustentabilidade do Sistema Faxinal a subordinação } \\
\text { à agroindústria do fumo: a desagregação do Faxinal dos } \\
\underline{\text { Lemes no Município de Ipiranga - PR }}\end{array}$ & 2005 & $\begin{array}{l}\text { Bach. em } \\
\text { Geografia }\end{array}$ & C. L. LÖWEN SAHR \\
\hline Lucas Bonatelli MALHO & $\begin{array}{l}\text { A influência educacional na concepção dos jovens e ado- } \\
\text { lescentes faxinalenses: o Faxinal de Sete Saltos de Baixo-PR }\end{array}$ & 2006 & $\begin{array}{l}\text { Bach. em } \\
\text { Geografia }\end{array}$ & L. A. G. CUNHA \\
\hline Everaldo Skalinski FERREIRA & $\begin{array}{l}\text { Evolução do uso da terra na bacia hidrográfica do rio } \\
\text { Sete Saltos, Ponta Grossa (PR) 1980-2006 }\end{array}$ & 2006 & $\begin{array}{l}\text { Bach. em } \\
\text { Geografia }\end{array}$ & S. M. CARVALHO \\
\hline Rodrigo Rocha MONTEIRO & $\begin{array}{l}\text { Populações Tradicionais e representações sociais: refle- } \\
\text { xões a partir de uma Comunidade Faxinalense }\end{array}$ & 2006 & $\begin{array}{l}\text { Bach. em } \\
\text { Geografia }\end{array}$ & C. L. LÖWEN SAHR \\
\hline Felipe Damásio da GUIA & $\begin{array}{l}\text { Classificação do uso da terra no Faxinal Taquari dos } \\
\underline{\text { Ribeiros }}\end{array}$ & 2007 & $\begin{array}{l}\text { Bach. em } \\
\text { Geografia }\end{array}$ & S. R. A. RIBEIRO \\
\hline Wladimir Teixeira SCHUSTER & $\begin{array}{l}\text { Articulações entre transformações no uso da terra e (des) } \\
\text { agregações no modo de vida: reflexões sobre o Faxinal } \\
\text { Saudade Santa Anita Turvo - PR }\end{array}$ & 2007 & $\begin{array}{l}\text { Bach. em } \\
\text { Geografia }\end{array}$ & C. L. LÖWEN SAHR \\
\hline Tiago Augusto BARBOSA & $\begin{array}{l}\text { Território e Territorialidades do Sistema Faxinal: Análise } \\
\text { a partir da reconstrução histórica familiar na comunidade } \\
\text { Taquari dos Ribeiros em Rio Azul/PR }\end{array}$ & 2007 & $\begin{array}{l}\text { Bach. em } \\
\text { Geografia }\end{array}$ & C. L. LÖWEN SAHR \\
\hline $\begin{array}{l}\text { Ana Paula Aparecida Ferreira } \\
\text { ALVES }\end{array}$ & $\begin{array}{l}\text { Geografia ensinada - Geografia vivida: conceitos e aborda- } \\
\text { gens ensinados e praticados no Faxinal Taquari dos Ribeiros }\end{array}$ & 2008 & $\begin{array}{l}\text { Lic. em } \\
\text { Geografia }\end{array}$ & C. L. LÖWEN SAHR \\
\hline Ingrid Aparecida GOMES & $\begin{array}{l}\text { Espacialização dos solos do Faxinal Taquari dos Ribeiros: } \\
\text { uma abordagem etnopedológica utilizando Geotecnologias }\end{array}$ & 2008 & $\begin{array}{l}\text { Bach. em } \\
\text { Geografia }\end{array}$ & S. R. A. RIBEIRO \\
\hline Nayme NEIVERTH & $\begin{array}{l}\text { O Estado moderno e as comunidades tradicionais: o caso } \\
\text { do Faxinal Taquari dos Ribeiros - Rio Azul, PR }\end{array}$ & 2010 & $\begin{array}{l}\text { Bach. em } \\
\text { Geografia }\end{array}$ & C. L. LÖWEN SAHR \\
\hline Juliano STRACHULSKI & $\begin{array}{l}\text { Plantas indicadoras da qualidade das terras e etnoconhe- } \\
\text { cimento no Faxinal Taquari dos Ribeiros, Município de } \\
\text { Rio Azul - } \mathrm{PR}\left({ }^{*}\right)\end{array}$ & 2011 & $\begin{array}{l}\text { Bach. em } \\
\text { Geografia }\end{array}$ & Nicolas FLORIANI \\
\hline Adelita STANINSKI & $\begin{array}{l}\text { Conhecimentos tradicionais e usos de plantas medicinais na } \\
\text { comunidade Faxinal Sete Saltos de Baixo - Ponta Grossa }\left(^{*}\right)\end{array}$ & 2011 & $\begin{array}{l}\text { Lic. Em } \\
\text { Geografia }\end{array}$ & Nicolas FLORIANI \\
\hline
\end{tabular}

Nota.: $\left(^{*}\right)$ Em andamento.

Fonte: Plataforma Lattes CNPq.

Com relação à pós-graduação da UEPG, os estudos sobre faxinais estão presentes tanto no curso de Especialização em Gestão Ambiental promovido pelo Departamento de Engenharia Civil e pelo Núcleo de Estudos em Meio Ambiente (Nucleam), como no curso de Mestrado em Gestão do Território do Programa de Pós-Graduação em Geografia.
No curso de Especialização em Gestão Ambiental foram integralizados três estudos no ano de 2007 (Quadro 05), todos orientados pela Profa. Dra. Rosemeri Segecin Moro, professora do Departamento de Biologia, mas também integrante do Mestrado em Gestão do Território. 
Quadro 05 - Trabalhos de Conclusão de Cursos de Especialização da UEPG sobre a temática Faxinal - 2007

\begin{tabular}{|l|l|l|l|l|}
\hline Nome & Título & Ano & Curso & Orientador \\
\hline $\begin{array}{l}\text { Christian } \\
\text { DYKSTRA }\end{array}$ & $\begin{array}{l}\text { Levantamento Fitossociológico do Faxinal Paraná-Anta Gorda, } \\
\text { Município de Prudentópolis, PR }\end{array}$ & 2007 & $\begin{array}{l}\text { Especialização em } \\
\text { Gestão Ambiental }\end{array}$ & R. S. MORO \\
\hline $\begin{array}{l}\text { Ariane C. } \\
\text { BITTENCOURT }\end{array}$ & $\begin{array}{l}\text { Caracterização da vegetação arbórea do Faxinal Saudade Santa } \\
\text { Anita, Turvo, PR }\end{array}$ & 2007 & $\begin{array}{l}\text { Especialização em } \\
\text { Gestão Ambiental }\end{array}$ & R. S. MORO \\
\hline $\begin{array}{l}\text { Christiane } \\
\text { NIEDZIELSKI }\end{array}$ & $\begin{array}{l}\text { Caracterização da vegetação arbórea do Faxinal Sete Saltos de } \\
\text { Baixo, Ponta Grossa, PR }\end{array}$ & 2007 & $\begin{array}{l}\text { Especialização em } \\
\text { Gestão Ambiental }\end{array}$ & R. S. MORO \\
\hline
\end{tabular}

Fonte: Plataforma Lattes CNPq.

Quadro 06 - Dissertação de Mestrado da UEPG sobre a temática Faxinal - 2008-2011

\begin{tabular}{|c|c|c|c|c|c|}
\hline Nome & Título & Ano & Bolsa & Curso & Orientador \\
\hline Patrícia FERREIRA & $\begin{array}{l}\text { Estudo sobre os Faxinais Lageado de Baixo } \\
\text { e Lageado dos Mello - PR: A construção de } \\
\text { conhecimento a partir da ecologia social } \\
\text { como subsídio para um projeto de turismo } \\
\text { comunitário }\end{array}$ & 2008 & Capes & $\begin{array}{l}\text { Mestrado } \\
\text { em Ciências } \\
\text { Sociais Apli- } \\
\text { cadas }\end{array}$ & $\begin{array}{l}\text { C. L. LÖWEN } \\
\text { SAHR }\end{array}$ \\
\hline Marcelo BARRETO & $\begin{array}{l}\text { A produção camponesa e o monopólio do } \\
\text { território pelo capital: espacialidades distintas } \\
\text { na extração da erva-mate na região da Floresta } \\
\text { com Araucária do Paraná }\end{array}$ & 2008 & Capes & $\begin{array}{l}\text { Mestrado } \\
\text { em Gestão } \\
\text { do Território }\end{array}$ & $\begin{array}{l}\text { C. L. LÖWEN } \\
\text { SAHR }\end{array}$ \\
\hline $\begin{array}{l}\text { Everaldo Skalisnki FER- } \\
\text { REIRA }\end{array}$ & $\begin{array}{l}\text { Diagnóstico Físico-Conservacionista (DFC) } \\
\text { para a bacia hidrográfica do rio Sete Saltos, com } \\
\text { presença de Faxinal, Ponta Grossa/PR }\end{array}$ & 2009 & $\begin{array}{l}\text { Fund. } \\
\text { Arau- } \\
\text {-cária }\end{array}$ & $\begin{array}{l}\text { Mestrado } \\
\text { em Gestão } \\
\text { do Território } \\
\end{array}$ & S. M. CARVALHO \\
\hline $\begin{array}{l}\text { Pedro Henrique Sanches } \\
\text { LEMES }\end{array}$ & $\begin{array}{l}\text { Turismo Comunitário e Populações Tradicio- } \\
\text { nais: o caso do Faxinal da Barra Bonita no mu- } \\
\text { nicípio de Prudentópolis - PR }\end{array}$ & 2009 & --- & $\begin{array}{l}\text { Mestrado } \\
\text { em Gestão } \\
\text { do Território }\end{array}$ & $\begin{array}{l}\text { C. L. LÖWEN } \\
\text { SAHR }\end{array}$ \\
\hline Willian SIMÕES & $\begin{array}{l}\text { Comunidades tradicionais de faxinais e gestão } \\
\text { de políticas públicas educacionais no Estado do } \\
\text { Paraná: compreendendo territórios e territoria- } \\
\text { lidades }\end{array}$ & 2009 & -- & $\begin{array}{l}\text { Mestrado } \\
\text { em Gestão } \\
\text { do Território }\end{array}$ & $\begin{array}{l}\text { C. L. LÖWEN } \\
\text { SAHR }\end{array}$ \\
\hline Douglas GRZEBIELUKA & $\begin{array}{l}\text { Comunidades de faxinal e suas dinâmicas sócio- } \\
\text {-espaciais: da formação à desagregação de uma } \\
\text { tradição no município de Tibagi (PR) na gênese } \\
\text { de localidades rurais }\end{array}$ & 2010 & -- & $\begin{array}{l}\text { Mestrado } \\
\text { em Gestão } \\
\text { do Território }\end{array}$ & $\begin{array}{l}\text { C. L. LÖWEN } \\
\text { SAHR }\end{array}$ \\
\hline Tiago Augusto BARBOSA & $\begin{array}{l}\text { Estruturação Familiar e Capital Social em Fa- } \\
\text { xinais: o caso de Taquari dos Ribeiros em Rio } \\
\text { Azul/PR }\end{array}$ & 2010 & -- & $\begin{array}{l}\text { Mestrado } \\
\text { em Gestão } \\
\text { do Território }\end{array}$ & $\begin{array}{l}\text { C. L. LÖWEN } \\
\text { SAHR }\end{array}$ \\
\hline Wladimir Teixeira SCHUSTER & Faxinais e região: o estudo do Paraná Tradicional & 2010 & $\begin{array}{l}\text { Fund. } \\
\text { Arau- } \\
\text {-cária }\end{array}$ & $\begin{array}{l}\text { Mestrado } \\
\text { em Gestão } \\
\text { do Território }\end{array}$ & L. A. G. CUNHA \\
\hline Ingrid Aparecida GOMES & $\begin{array}{l}\text { Mapeamento preditivo de solos do Faxinal } \\
\text { Taquari dos Ribeiros - PR: uma abordagem com } \\
\text { o uso das Geotecnologias }\end{array}$ & 2011 & $\begin{array}{l}\text { Fund. } \\
\text { Arau- } \\
\text {-cária }\end{array}$ & $\begin{array}{l}\text { Mestrado } \\
\text { em Gestão } \\
\text { do Território }\end{array}$ & S. R. A. RIBEIRO \\
\hline
\end{tabular}

Fonte: Plataforma Lattes CNPq.

Obs.: Em andamento no Mestrado em Gestão do Território encontram-se as dissertações de Andréa Aparecida Inácio da SILVA com título provisório "Etnogeografia: saberes vernaculares e território da exploração agrícola em um Faxinal paranaense", orientada pelo professor N. FLORIANI,e a de Joélcio Gonçalves SOARES com título provisório "Gênese, estrutura e dinâmica de povoamento em faxinais: um estudo sobre comunidades rurais no município de Rio Azul-PR", orientada pela professora C. L. LÖWENSAHR. Ambas com previsão de defesa para início de 2012. 
Em nível de mestrado (Quadro 06), observa-se certo distanciamento temporal com relaçãoaos trabalhos de iniciação científica e de monografias de conclusão de curso, com os primeiros estudos despontando apenas em 2008. Em 2008 concluiram-se as primeiras dissertações do Curso de Mestrado em Gestão do Território da UEPG, tendo em vista que o mesmo foi implantado em 2006. Interessante é observar, que a maioria dos mestrandos com temática sobre faxinais, concluintes das dissertações em 2008 e 2009, não tem vínculo anterior com a temática, $\mathrm{e}$ que alguns dos primeiros acadêmicos iniciantes dos estudos de faxinais como bolsistas de iniciação científica e/ou trabalho de conclusão de curso de graduação, concluem a dissertação de mestrado sobre faxinais em 2010 e 2011.

No momento atual, vivencia-se uma fase em que alguns dos acadêmicos formados na UEPG, seja na graduação ou na pós-graduação, encontram-se vinculados a outros programas de pós-graduação, e mantém a temática dos faxinais. Um exemplo é o Msc. Rodrigo Rocha Monteiro, que fez iniciação científica e monografia de graduação na UEPG com a temática faxinais, na sequência fez o mestrado na UFSC com o Prof. Dr. Nazareno José de Campos mantendo a temática, e hoje se encontra em doutoramento na UNESP-RC com a Profa. Dra. Bernadete Aparecida Caprioglio de Castro Oliveira. Outro caso é o do Msc. Marcelo Barreto, que concluiu o mestrado na UEPG com a temática faxinais, e hoje se encontra em doutoramento na USP com a Profa. Marta Inez Medeiros Marques, mantendo a temática.

\section{CONSIDERAÇÕES FINAIS}

A pesquisa extensionista, de forma geral, tem múltiplos aspectos a serem con- siderados e que envolvem uma reflexão profunda acerca do papel das universidades diante da sociedade da qual fazem parte. No caso específico da pesquisa extensionista da UEPG em faxinais, há que se ressaltar que estas permitem o contato dos acadêmicos, em processo de formação, com uma realidade rural pouco conhecida, embora presente na região onde se insere a UEPG. Por tratar-se de comunidades frágeis diante dos processos de avanço do capitalismo, elas precisam de auxílio para que possam continuar a existir e para que esta existência tenha garantia de dignidade. Estes dois aspectos garantem a relevância acadêmica e social dos projetos que vem sendo desenvolvidos na universidade.

Por meio dos diferentes projetos desenvolvidos tornou-se possível a articulação entre o ensino, a pesquisa e a extensão. $\mathrm{O}$ retorno do conhecimento adquirido pelo contato com a realidade para a sala de aula garante uma realimentação do ensino, garantindo sua dinâmica e atualidade. A participação de pesquisadores em diferentes fases acadêmicas (doutores, mestres, especialistas, graduados e graduandos) nos projetos, possibilita uma formação mais crítica aos acadêmicos envolvidos, bem como, que as ações, bem como o pensar sobre estas, sejam sistematizados e refletidos em bases científicas renovadas.

As publicações dos docentes e discentes direta e indiretamente envolvidos nos projetos comprovam a articulação entre a extensão e a pesquisa. A inserção dos projetos em uma rede de pesquisa e em uma rede que reúne atores do processo de desenvolvimento regional permite que as experiências e conhecimentos adquiridos com os faxinalenses possam concretizar-se em diretrizes de ação para o reconhecimento destes como populações tradicionais e territórios sociais que necessitam de políticas públicas específicas que garantam suas particularidades e seus potenciais. 


\section{PRODUÇÃO CIENTÍFICA DA UEPG SOBRE FAXINAIS ${ }^{4}$}

\section{Capítulo de livro internacional publicado}

SAHR, W.; LÖWENSAHR, C. L. L. Faxinal-ökologisch integrierte Landwirtschaft zwischen Mittelalter und Postmoderne in Südbrasilien. In: GLASSER, R.; KREMB, K. (Org.). Planet Erde-Nord u. Südamerika (Amerika 2). Darmstadt, 2006, p. 207-218. (Tradução: Faxinal - agricultura ecologicamente integrada entre a idade média e a pós-modernidade).

\section{Capítulos de livro nacional publicado}

LÖWEN SAHR, C. L. O pré-moderno na pósmodernidade: refletindo sobre as comunidades de faxinais da Floresta com Araucária do Paraná. In: MARAFON, G.; RUA, J.; RIBEIRO, M. A. (Org.). Abordagens teórico-metodológicas em Geografia Agrária. Rio de Janeiro: Eduerj, 2007, p. 208-223.

LÖWEN SAHR, C. L.; SAHR, W. D.Territóriosfaxinais-espaços. A problemática espaço/território na formação social brasileira. In: SAQUET, M. e SPOSITO, E. (Org.). Territórios e territorialidades: teorias, processos e conflitos. São Paulo: Expressão Popular, 2009, p. 143-173.

LÖWEN SAHR, C. L. A questão socioambiental dos Faxinais paranaenses: caminhos para se pensar numa pedagogia holística e integrativa. In: SEEDPR. (Org.). Caderno Educação Ambiental na Escola. Curitiba: SEED-PR, 2011.

\section{Artigos completos publicados em periódicos internacionais}

LÖWEN SAHR, C. L. . La cuestión socioambiental em comunidades tradicionales de faxinais en Paraná, Brasil: reflexiones sobre una pedagogia holística e integrativa. Didacticas específicas, Madri, v. 1, p. 1-11, 2009.

\footnotetext{
${ }^{4}$ Os Projetos de Pesquisa e Extensão, bem como, os Relatórios de Iniciação Científica, as Monografias de Graduação e Especialização, e as Dissertações de Mestrado não são aqui relacionados, todavia, suas informações constam nos Quadros que compõe o artigo.
}

\section{Artigos completos publicados em periódicos nacionais}

LÖWEN SAHR, C. L. Preservação e revitalização do Sistema Faxinal na Região da Mata de Araucária do Paraná: um Projeto Extensionista. Revista ConexãoUepg, Ponta Grossa, v. 1, n. 1, p.42-46, 2005.

LÖWENSAHR, C. L.; CUNHA, L. A. G. Osignificado social e ecológico dos Faxinais: reflexões a cerca de uma política agrária sustentável para a região da Mata de Araucária no Paraná. Emancipação, Ponta Grossa, v. 5, n. 1, p. 89-104, 2005.

LÖWEN SAHR, C. L.; CUNHA, L. A. G.; CARVALHO, S. M.; SAHR, W. D.; PRIETO, C. C.; LEMES, E. C.; SOARES, I. S.; MALHO, L. B.; MALUF, P. S.; MONTEIRO, R. R.; BARBOSA, T. A. Pela defesa de povos e terras de Faxinais: reflexões sobre uma ação extensionista. Extensão (UFPel), Florianópolis, v. 10, n. 2, p. 1-10, 2005.

BARRETO, M.; LÖWEN SAHR, C. L. Os Faxinais e a Erva Mate: a incorporação da produção camponesa ao movimento da indústria capitalista. Terra Plural, v. 1, p. 75-86, 2007.

LÖWENSAHR, C. L. Os "mundos faxinalenses" da floresta com araucária do Paraná: racionalidades duais em comunidades tradicionais. Terra Plural, Ponta Grossa, v. 2, p. 213-226, 2008.

SIMÕES, W.;LÖWENSAHR, C. L. Asterritorialidades dos faxinalenses e as políticas públicas educacionais do estado do Paraná: compreendendo realidades, problematizando limites e as possibilidades. Terra Plural, Ponta Grossa, v. 2, p. 115-132, 2008.

ALVES, A. P. A. F. ; LÖWEN SAHR, C. L. Geografia ensinada - geografia vivida? Conceitos e abordagens para o ensino fundamental no Paraná. Expressões Geográficas, Florianópolis, v. 5, p. 49-60, 2009.

GRZEBIELUKA, D.; LÖWEN SAHR, C. L. Comunidades de Faxinal e suas dinâmicas socioespaciais: da formação à desagregação de uma tradição no município de Tibagi (PR) - um estudo sobre o Faxinal dos Empoçados. Revista Geografar (UFPR), Curitiba, v. 4, p. 34-58, 2009.

LÖWEN SAHR, C. L. A questão socioambiental dos Faxinais paranaenses: caminhos para se pensar numa pedagogia holística e integrativa. Percurso, Curitiba, v. 8, p. 53-66, 2009.

SCHUSTER, W. T.; LÖWENSAHR, C. L. OFaxinal do Presente e o Faxinal do Passado: Transformações no uso da terra no Faxinal Saudade Santa Anita - Turvo/ PR. Publicatio UEPG, Ponta Grossa, v. 15, p. 7-18, 2009. 
GOMES, I. A.; RIBEIRO, S. R. A. Espacialização etnopedológica das terras do Faxinal Taquari dos Ribeiros - PR: uma abordagem com uso das geotecnologias. Terra Plural, v. 4, p. 65-76, 2010.

MOREIRA, J. C.; SANTOS, V. M. M.; GARCIA, J. N.; PAZ, J. A. O Roteiro dos Faxinais em Prudentópolis - PR - Ecoturismo como ferramenta de Desenvolvimento Sustentável. Revista Brasileira de Ecoturismo, São Paulo, v. 4, p. 95-110, 2011.

SOARES, J. G.; LÖWEN SAHR, C. L. Mudanças socioambientais em comunidades tradicionais de Faxinal: um estudo de caso da (des)tradicionalização deste modo de vida em comunidades rurais. P@ rtes, São Paulo, v. 1, p. 1-9, 2011.

PEREIRA, T. K.; CHAVES, C. C.; MACHADO, N. C.; FLORIANI, N.; MORO, R. S. Fitossociologia do criadouro comunitário do Faxinal Taquari dos Ribeiros, Rio Azul - PR. Cadernos do IAPAR, 2011 (no prelo).

FLORIANI, N.; CARVALHO, S. M. ; FLORIANI, D.; SILVA, A. I. P.; STRACHULKI, J. Modelos híbridos de agricultura em um faxinal paranaense: confluência de imaginários e de saberes sobre paisagens. Geografia, Rio Claro. 2011(no prelo).

\section{Trabalhos completos em anais de eventos internacionais}

LEMES, E. C.; LÖWEN SAHR, C. L. Da subsistência do Sistema Faxinal à subordinação à agroindústria do fumo: a desagregação do Faxinal dos Lemes no Município de Ipiranga - PR. In: II Simpósio Internacional de Geografia Agrária, 2005, Presidente Prudente. Anais do II SINGA. 2005.

LÖWEN SAHR, C. L. Povos Tradicionais e Territórios sociais: Reflexões acerca dos povos e das terras de faxinal do Bioma da Mata com Araucária. In: II Simpósio Internacional de Geografia Agrária, 2005, Presidente Prudente. Anaisdo II SINGA. 2005. p. 1-15.

LÖWEN SAHR, C. L.; CUNHA, L. A. G. Sistema Faxinal: caboclos entre a idade média e a pósmodernidade. In: 10. Encontro de Geógrafos da América Latina, 2005, São Paulo. Anais do 10. EGAL. São Paulo: USP, 2005. p. 13131-13143.

MONTEIRO, R. R.; LÖWEN SAHR, C. L. O Sistema Faxinal enquanto forma de organização cabocla: o caso do Faxinal Sete Saltos de Baixo em Ponta Grossa - PR. In: II Simpósio Internacional de Geografia Agrária, 2005, Presidente Prudente. Anaisdo II SINGA. 2005. p. 1-14.

BARRETO, M.; LÖWEN SAHR, C. L. A (re) produção camponesa na produção da erva-mate: relação entre os Faxinais e a indústria ervateira na região da Floresta com Aracucária do Paraná. In: III Simpósio Internacional de Geografia Agrária, 2007, Londrina. Anais do III SINGA. Londrina: Eduel, 2007. p. 1-13.

LEMES, P. H. S.; LÖWEN SAHR, C. L. Turismo em comunidades Tradicionais: uma alternativa para os Faxinais do Município de Prudentópolis - PR. In: IX Seminário Internacional de Turismo, 2007, Curitiba. Anais do IX SIT. Curitiba: Unicenp, 2007. p. 1-13.

LÖWEN SAHR, C. L. Comunidades Tradicionais em Sociedades Modernas: Reflexões sobre as racionalidades Duais nos Faxinais do Paraná. In: III Simpósio Internacional de Geografia Agrária, 2007, Londrina. Anais do III SINGA. Londrina: UEL, 2007. p. 1-14.

SCHUSTER, W. T.; LÖWEN SAHR, C. L. Resistências e Contradições: A luta do Faxinal Saudade Santa Anita - Turvo/PR. In: III Simpósio Internacional de Geografia Agrária, 2007, Londrina. Anais do III SINGA. Londrina : UEL, 2007. p. 1-12.

SAHR, W. D.; LÖWEN SAHR, C. L. A problemática espaço/território a partir de geograficidades existenciais: as comunidades faxinalenses no Brasil Meridional. In: 12. Encontro de Geógrafos da América Latina, 2009, Montevideo. Anais do 12. EGAL. Montevideo, 2009. p. 1-15.

PEREIRA, T. K.; CHAVES, C. C.; MACHADO, N.; FLORIANI, N.; MORO, R. S. Fitossociologia do Criadouro Comunitário do Faxinal Taquari dos Ribeiro,Rio Azul/PR. In: 1. Seminário Internacional de Ciência, Tecnologia e Ambiente, 2009, Cascavel. Anais do 1. SICTA. Cascavel: Unioeste, 2009. p. 1-9.

\section{Trabalhos completos em anais de eventos nacionais}

IEGELSKI, F; LÖWENSAHR, C. L. Cultura cabocla, sistema faxinal e turismo: o Faxinal da Linha Paraná em Prudentópolis. In: 1. Encontro Regional Sulbrasileiro de Geografia, 2003, Curitiba. Anais do 1. Ensulgeo. Curitiba: 2003. p. 146-156.

LÖWEN SAHR, C. L.; IEGELSKI, F. A dissolução de um recanto feliz: o sistema faxinal no município 
de Ponta Grossa - PR. In: IV Congresso Brasileiro de Pesquisas Ambientais e Saúde, 2004, Santos. Anais do IV CBPAS. Santos: ABPAS, 2004. p. 145-155.

LÖWEN SAHR, C. L.Faxinalenses: populações tradicionais no Bioma da Mata com Araucária? In: I Encontro dos Povos de Faxinais, 2005, Irati. Anais do I EPF. Curitiba: IAP/SEMA, 2005. p. 53-62.

LÖWEN SAHR, C. L. Os Faxinais enquanto populações tradicionais e territórios sociais: algumas reflexões. In: VI Encontro Nacional da Anpege, 2005, Fortaleza. Anais do VI Enanpege. Fortaleza: Anpege, 2005. p. 1-15.

BARRETO, M.; LÖWENSAHR, C. L.A Expansão do Capital Ervateiro e o Modo Faxinalense de Produção no Município de Rebouças Estado do Paraná. In: XVIII Encontro Nacional de Geografia Agrária, 2006, Rio de Janeiro. Anais do XVIII ENGA. Rio de Janeiro: UERJ, 2006. p. 1-17.

BARRETO, M.; LÖWEN SAHR, C. L. A produção da erva-mate e o desenvolvimento regional: o caso da região da Floresta com Araucária no Paraná. In: 1. Seminário de Pesquisa do Mestrado em Gestão do Território, 2006, Ponta Grossa. Anais do 1. SPMFT. Ponta Grossa: UEPG, 2006. p. 1-10.

CARVALHO, S. M., BARBOSA, T. A. O Diagnóstico Rural participativo como instrumento para levantamento de dados. O Exemplo do Faxinal dos Seixas no Município de São João do Triunfo-PR. In: XVIII Encontro Nacional de Geografia Agrária, 2006, Rio de Janeiro. Anais do XVIII ENGA. Rio de Janeiro: UERJ, 2006. p. 1-15.

FERREIRA, P.; LÖWEN SAHR, C. L.; OLIVEIRA JR., C. R. O olhar do turista sobre o rito ucraínocaboclo da Páscoa dos Faxinais Lageado de Baixo e Lageado dos Mellos nos Municípios de Mallet e Rio Azul - PR. In: II Encontro Paranaense de Pesquisa e Extensão, 2006, Foz do Iguaçu. Anais do II EPPE. Foz do Iguaçu: 2006. p. 1-14.

LÖWEN SAHR, C. L.O pré-moderno na pósmodernidade: refletindo sobre as comunidades de faxinais da Floresta com Araucária do Paraná. In: XVIII Encontro Nacional de Geografia Agrária, 2006, Rio de Janeiro. Anais do XVIII ENGA. Rio de Janeiro: UERJ, 2006. p. 1-18.

PRIETO, C. C.; CUNHA, L. A. G.; LÖWEN SAHR, C. L. Sistema Faxinal e suas Populações Tradicionais: exemplos do Faxinal Paraná Anta Gorda, Prudentópolis, Paraná. In: XIV Encontro Nacional de Geógrafos, 2006, Rio Branco - AC. Anais do XIV ENG. Rio Branco: AGB, 2006. p. 1-15.
SCHUSTER,W.T.;LÖWENSAHR,C.L.Generalidades e particularidades do sistema faxinal: o caso do Faxinal Saudade Santa Anita no Município de Turvo (PR). In: XVIII Encontro Nacional de Geografia Agrária, 2006, Rio de Janeiro. Anais do XVIII ENGA. Rio de Janeiro: UERJ, 2006. p. 1-15.

BARBOSA, T. A.; CARVALHO, S. M. A dinâmica espacial do Faxinal dos Seixas no contexto da bacia hidrográfica do rio dos Fabrícios em São João do Triunfo PR. In: XII Simpósio Brasileiro de Geografia Física Aplicada, 2007, Natal. Anais do XII SBGFA. Natal: UFRN, 2007. v. 1. p. 1502-1513.

BARRETO, M.; LÖWEN SAHR, C. L.A Retomada da Extração e Beneficiamento da Erva-Mate: uma alternativa para os Faxinais na Região da Floresta com Araucária do Paraná. In: II Simpósio Paranaense de Pós-Graduação em Geografia, 2007, Londrina. Anais do II Simpgeo. 2007. Londrina: UEL, 2007. p. 1-8.

BARRETO, M.; LÖWEN SAHR, C. L. A Produção Camponesa na Região da Floresta com Araucária do Paraná: Reflexões acerca da erva-mate e do Sistema Faxinal. In: VII Encontro Nacional da Anpege, 2007, Niterói. Anais do VII Enanpege. Niterói: Anpege, 2007. p. 1-12

GRZEBIELUKA, D.; LÖWEN SAHR, C. L. Comunidades de Faxinal e suas dinâmicas sócioespaciais: da formação à desagregação de uma tradição no município de Tibagi - PR. In: II Simpósio Paranaense de Pós-Graduação em Geografia, 2007, Londrina. Anais do II Simpgeo. 2007. Londrina: UEL, 2007. p. 1-23.

FERREIRA, E. S.; CARVALHO, S. M. Setorização como ferramenta de potencialização da compreensão do uso da terra na bacia hidrográfica do rio Sete Saltos PR com a presença do sistema faxinal. In: II Seminário de Pesquisa do Mestrado em Gestão do Território, 2007, Ponta Grossa. Anais do II SPMGT. Ponta Grossa: UEPG, 2007. p. 11-27.

FERREIRA, E. S.; CARVALHO, S. M. Evolução Têmporo-espacial no Uso da Terra em uma Bacia Hidrográfica com a presença do Sistema Faxinal. In: II Simpósio Paranaense de Pós-Graduação em Geografia, 2007, Londrina. Anais do II Simpgeo.2007. Londrina: UEL, 2007. p. 1-15.

LEMES, P. H. S.; LÖWEN SAHR, C. L. Turismo em Comunidades Tradicionais: uma alternativa para os Faxinais do Município de Prudentópolis - PR. In: II Simpósio Paranaense de Pós-Graduação em Geografia, 2007, Londrina. Anais do II Simpgeo. 2007. Londrina: UEL, 2007. p. 1-13. 
LEMES, P. H. S.; LÖWEN SAHR, C. L. O turismo de base comunitária como fator de fortalecimento identitário de populações tradicionais: reflexões sobre os faxinais do município de Prudentópolis (PR). In: II Seminário de Pesquisa do Mestrado em Gestão do Território, 2007, Ponta Grossa. Anais do II SPMGT. Ponta Grossa: UEPG, 2007. p. 143-160.

LÖWEN SAHR, C. L. Comunidades Tradicionais em Racionalidades Duais: Reflexões sobre os Povos de Faxinais. In: VII Encontro Nacional da Anpege, 2007, Niterói. Anais do VII Enanpege. Niterói: Anpege, 2007. p. 1-12

SCHUSTER, W. T.; BARRETO, M.; LÖWEN SAHR, C. L. Agricultura ecológica como alternativa para Faxinais: reflexões a partir do Faxinal Saudade Santa Anita - Turvo/PR. In: III Seminário Estadual de Estudos Territoriais, 2007, Francisco Beltrão. Anais do III SEET. Francisco Beltrão: UNIOESTE, 2007. p. 1-12.

SIMÕES, W.; LÖWEN SAHR, C. L. As Territorialidades dos Povos do Campo e as Políticas Educacionais: Articulações e Desarticulações. In: II Simpósio Paranaense de Pós-Graduação em Geografia, 2007, Londrina. Anais do II Simpgeo. 2007. Londrina: UEL, 2007. p. 1-15.

SIMÕES, W.; LÖWEN SAHR, C. L. As territorialidades dos povos faxinalenses e as políticas educacionais do estado do Paraná: Compreendendo realidades, problematizando limites e buscado possibiliidades. In: II Seminário de Pesquisa do Mestrado em Gestão do Território, 2007, Ponta Grossa. Anais do II SPMGT. Ponta Grossa: UEPG, 2007. p. 289-207.

BARBOSA, T. A.; LÖWEN SAHR, C. L. Território e Territorialidades nas relações familiares: estudo sobre a comunidade faxinalense de Taquari dos Ribeiros. In: III Seminário de Pesquisa do Mestrado em Gestão do Território, 2008, Ponta Grossa. Anais do III SPMGT. Ponta Grossa: UEPG, 2008. p. 1-17.

BARBOSA, T. A.; LÖWEN SAHR, C. L. A Multiterritorialidade dos Faxinais e suas Dimensões. In: XIIIEncontro Paranaense de Estudantes de Geografia, 2008, Marechal Cândido Rondon. Anais do XIII EPEG. Marechal Cândido Rondon: Unioeste, 2008. p. 1-12.

BARBOSA, T. A.; LÖWEN SAHR, C. L. Território e territorialidade nas relações familiares: estudo sobre a comunidade faxinalense de Taquari dos Ribeiros. In: III Simpósio Paranaense de Pós-Graduação em Geografia, 2008, Ponta Grossa. Anais do III Simpgeo. Ponta Grossa: UEPG, 2008. p. 1-15.
FERREIRA, E. S.; CARVALHO, S. M. Conflitos de uso da terra na bacia hidrográfica do rio Sete Saltos - PR com a presença do Sistema Faxinal. In: III Simpósio Paranaense de Pós-Graduação em Geografia, 2008, Ponta Grossa. Anais do III Simpgeo. Ponta Grossa: UEPG, 2008. p. 194-207.

GOMES, I. A.; RIBEIRO, S. R. A. Fusão de imagens SPOT5 para a classificação qualitativa do uso e cobertura do solo no Faxinal Taquari dos Ribeiros - PR. In: 9. Congresso de Cadastro Técnico Multifinalitário e Gestão Territorial, 2008, Florianópolis. Anais do 9. COBRAC. Florianopólis: Ed UFSC, 2008.

GRZEBIELUKA, D.; LÖWEN SAHR, C. L. Comunidades de faxinal e suas dinâmicas sócioespaciais: da formação à desagregação de uma tradição no Município de Tibagi (PR). In: III Seminário de Pesquisa do Mestrado em Gestão do Território, 2008, Ponta Grossa. Anais do III SPMGT. Ponta Grossa: UEPG, 2008. p. 1-22.

GRZEBIELUKA, D. ; LÖWEN SAHR, C. L. A fenomenologia de Husserl: reflexões acerca do método fenomenológico aplicado aos estudos dos Faxinais. In: III Encontro Sulbrasileiro de Geografia, 2008, Francisco Beltrão. Anais do III Ensulgeo. Francisco Beltrão: UNIOESTE, 2008. p. 101-110.

SCHUSTER, W. T.; LÖWEN SAHR, C. L. Passado e presente no Faxinal Saudade Santa Anita - Turvo/ PR: tranformações e permanências. In: III Simpósio Paranaense de Pós-Graduação em Geografia, 2008, Ponta Grossa. Anais do III Simpgeo. Ponta Grossa: UEPG, 2008. p. 1-15.

SIMÕES, W. ; LÖWEN SAHR, C. L. . O território da juventude e a juventude no território: aspectos da multiterritorialidade no Faxinal Taquari dos Ribeiros. In: III Simpósio Paranaense de PósGraduação em Geografia, 2008, Ponta Grossa. Anais do III Simpgeo. Ponta Grossa: UEPG, 2008. p. 1-15.

BARBOSA, T. A.; LÖWEN SAHR, C. L. (Trans) formações do território em comunidades tradicionais: o caso do Faxinal Taquari dos Ribeiros em Rio Azul - PR. In: VIII Encontro Nacional da Anpege, 2009, Curitiba. Anais do VIII Enanpege. Curitiba: Anpege, 2009. p. 1-15.

FERREIRA, E. S.; CARVALHO, S. M. Diagnóstico físico-conservacionista- DFC aplicado a bacia hidrográfica do rio Sete Saltos PR com a presença do sistema faxinal. In: $12^{\circ}$ Encontro de Geógrafos da América Latina, 2009, Montevidéu. Anais do 12. Egal. Montevideo: Easy Planners, 2009. p. 1-18. 
GOMES, I. A.; RIBEIRO, S. R. A.; GIAROLA, N. F. B. Espacialização dos solos do Faxinal Taquari dos Ribeiros: uma abordagem etnopedológica utilizando Geotecnologias. In: IX Seminário de Pós-Graduação em Geografia da UNESP em Rio Claro, 2009. Anais do IX SPGG-UNESP-RC. Rio Claro: PPGG, 2009. p. 1-16.

GRZEBIELUKA, D. ; LÖWEN SAHR, C. L. Estruturação agrária do município de Tibagi, Paraná: uma análise nos processos de formação das comunidades rurais sobre o ponto de vista da Gênese do Sistema Faxinal. In: VIII Encontro Nacional da Anpege, 2009, Curitiba. Anais do VIII Enanpege. Curitiba: Anpege, 2009. p. 1-16.

GRZEBIELUKA, D.; LÖWEN SAHR, C. L. Comunidades de Faxinal e suas dinâmicas sócioespaciais: da formação a desagregação de uma tradição no centro-sul do Paraná. In: II Seminário sobre múltiplas territorialidades, 2009, Francisco Beltrão. Anais do II SMT. Francisco Beltrão: UNIOESTE, 2009. p. 1299-1311.

NEIVERTH, N.; LÖWEN SAHR, C. L. Fumicultura, doença e morte no Faxinal Taquari dos Ribeiros (Rio Azul/PR): reflexões a partir da Geografia da Saúde. In: XIV Encontro Paranaense de Estudantes de Geografia, 2009, Guarapuava. Anais do XIV EPEG. Guarapuava: Unicentro, 2009. p. 1-10.

SCHUSTER, W. T.; LÖWEN SAHR, C. L. O Faxinal do Presente e o Faxinal do Passado: evolução do uso da terra no Faxinal Saudade Santa Anita Turvo - PR. In: XIX Encontro Nacional de Geografia Agrária, 2009, São Paulo. Anais do XIX ENGA. São Paulo: USP, 2009. p. 1-17.

FLORIANI,N.;CARVALHO,S.M.;STRACHULSKI, J. Modelos híbridos de agricultura em um faxinal paranaense: confluência de imaginários e de saberes agrícolas. In: XX Encontro Nacional de Geografia Agrária, 2010, Francisco Beltrão. Anais do XX Enga. Francisco Beltrão: UNIOESTE, 2010. v. 1. p. $4784-4808$.
FLORIANI, N.; CARVALHO, S. M.; FLORIANI, D.; SILVA, A. A. I.; STRACHULSKI, J. Modelos híbridos de agricultura em um faxinal paranaense confluência de imaginários e de saberes agrícolas. In: V Encontro Nacional da ANPPAS, 2010, Florianópolis. Anais do ENANPPAS. Florianópolis: ANPPAS, 2010. p. 1-21.

FLORIANI, N.; PINTO, M. L. C.; LOMBARDI, A. P.; STANISKI, A. Processos Erosivos no SubSistema "Terras-de-Plantar" em Faxinal Paranaense com cultivo de fumo integrado. In: VIII Simpósio Nacional de Geomorfologia, 2010, Recife. Anais do VIII Sinageo. Recife: União da Geomorfologia Brasileira/UFPE, 2010. p. 1-15.

PEREIRA, T. K.; CHAVES, C. C.; Machado, N.; FLORIANI, N.; MORO, R. S. O Sistema Faxinal como elemento de preservação da floresta com Araucária In: IV Encontro da Rede de Estudos Rurais, 2010, Curitiba. Anais do IV Erer. Curitiba: UFPR, 2010. p.1-12.

SOARES, J. G.; LÖWEN SAHR, C. L. Gênese, estrutura e dinâmica de povoamento em Faxinais: um estudo sobre comunidades rurais no Município de Rio Azul - PR. In: V Seminário de Pesquisa do Mestrado em Gestão do Território da UEPG, 2010, Ponta Grossa. Anais do V SPMGT. Ponta Grossa: UEPG, 2010. p. 261-299.

\section{Relatórios Técnicos}

LÖWEN SAHR, C. L.; IEGELSKI, F. O Sistema Faxinal no Município de Ponta Grossa: Diretrizes para a preservação do ecossistema, do modo de vida, da cultura e das identidades das comunidades e dos espaços faxinalenses. Ponta Grossa: PMPG, 2003.

Recebido em: 03/10/11 Aceito em: 06/11/11 